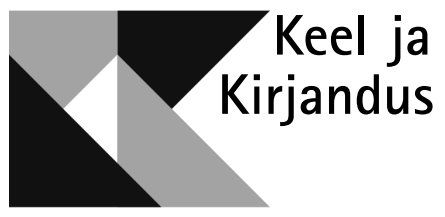

\title{
MIDA TEEB MOORA EESTI KEELES?
}

\author{
KÜLLI PRILLOP
}

$\mathrm{M}$

oora on antiikses värsiõpetuses defineeritud kui lühikese silbi hääldamiseks kuluv aeg. Tegemist on mõotühikuga, mis aitab eristada pikki ja lühikesi silpe. Moorasid pole aga vaja mitte ainult antiiksete värsside kirjeldamisel. Jaapani klassikaline luulevorm haiku koosneb täpselt 17 moorast, kusjuures jaapani keeles pole moora mitte pikkuse mõõtühik, vaid reaalne prosoodiline üksus. Iga moora jaoks on jaapani hiraganas ja katakanas oma märk. Moora on nagu silp, aga väiksem. Näiteks sõnas haiku on kaks silpi, ent kolm moorat.

Mõõtühikutest (olgu siis meetritest, vaksadest, jalgadest või mooradest) ei saa kuidagi suuremaid objekte kokku panna, need on abiks vaid esemete suuruse kirjeldamisel. Reaalseid objekte seevastu saab omavahel ühendada, aga neid saab kasutada ka teiste objektide mõõtmiseks. Segadust mooradega kas need on mõõtühikud või struktuuriüksused - aitabki ehk kõige paremini mõista võrdlus jalgadega: kui mingi ese on kaks jalga pikk, siis ei pruugi tema küljes olla ühtegi jalga, aga pikkus on umbkaudu 60 sentimeetrit; kahe jalaga objekt on aga näiteks inimene ja tema pikkus oleneb veel paljust muustki kui jalgade olemasolust.

Tänapäeva keeleteaduses on moora üldiselt kasutusel kui üksus, millest pannakse kokku silbid. Moorat peetakse universaalseks, st silbid koosnevad mooradest kõikides keeltes, mitte ainult jaapani keeles. Varem, XX sajandi keskpaiku, on moorat rakendatud ka pelgalt mõõtühikuna, kuid tolleaegses fonoloogiateoorias ei nähtudki vajadust hierarhilise prosoodilise struktuuri ega üldse mingite foneemist suuremate üksuste järele. 
Kuigi moora kui prosoodilise üksuse olemasolu ja universaalsus on praeguses teoreetilises fonoloogias üldiselt omaks võetud (vt nt käsiraamatut Zec 2007), väidavad Eesti foneetikud aeg-ajalt, et eesti keele kirjeldamiseks moora ei sobi. Moorat soovitakse näha kui mõõtühikut, millel peaks olema mingi kindla kestusega foneetiline korrelaat (viimati Lippus 2016: 121). Siinse artikli esimestes peatükkides selgitan, kuidas ja miks on kujunenud arusaamatused moora mõistmisel, seejärel kirjeldan eesti keele fonoloogilist süsteemi ja selle kujunemist tänapäevasest moorateooriast lähtuvalt. Tegemist on esimese osaga põhjalikumast eesti keele fonoloogilise struktuuri ja selle teisenemise uurimusest. Mõned siinsetest seisukohtadest olen esmalt avaldanud ingliskeelsena ajakirjas Linguistica Uralica (Prillop 2013) ning hiljem eestikeelsena Eesti ja Soome-Ugri Keeleteaduse Ajakirjas (Prillop 2015). Käesolevasse artiklisse olen lisanud uuemaid katsetulemusi ning nende tõlgendusi väldete kohta, leenis- ja fortisklusiilide käsitluse, samuti seni põhjalikema eestikeelse ülevaate moorateooriast ja selle kasutuselevõtu põhjustest. Eesmärgiks on näidata, et moorat on vaja mujalgi kui kolme välte süsteemi kirjeldamisel.

\section{Moora ajaloost keeleteaduses}

Antiikses värsiõpetuses tähendab moora lühikese silbi hääldamiseks kuluvat aega. Antiikaja värsisüsteem oli meetriline: värsis ei vaheldunud mitte rõhulised ja rõhuta silbid, vaid pikad ja lühikesed silbid. Tavalisim värsimõõt, heksameeter, koosnes kuuest värsijalast. Neli esimest neist olid harilikult daktülid, st sisaldasid ühte pikka ja kahte lühikest silpi. Kahe lühikese silbi asemel võis aga olla ka üks pikk, nii et värsijalg koosnes hoopis kahest pikast silbist. Pika silbi kestuseks oli kaks moorat ja see oli meetriliselt võrdväärne kahe lühikese silbiga. Tõsi, antiikaja õpetlased ise terminit moora ei kasutanud. William Sidney Alleni (1987: 112) andmetel võttis moora värsiõpetuse terminina esmakordselt kasutusele saksa klassikaline filoloog Gottfried Hermann XVIII sajandi lõpus (vt Hermann 1799: 23).

Keeleteaduses on moora olnud kasutusel vähemalt 1930. aastatest, kuid selle mõiste täpsem sisu on olnud autoriti üsna erinev. Nikolai Trubetzkoy (1939: 174) eristas moorasid loendavaid keeli ning silpe loendavaid keeli. Näiteks klassikaline ladina keel on Trubetzkoy määratluse järgi moorasid loendav keel. Ladina keele kolme- ja enamasilbilistes sõnades on rõhk eelviimasel silbil, kui see silp on pikk; aga kui eelviimane silp on lühike, on rõhk tagantpoolt lugedes kolmandal silbil. Arvestades, et lühikeses silbis on üks moora ja pikas silbis kaks, saab esitatud reeglit lihtsustada: rõhk asetseb eelviimasel mooral enne viimast silpi (joonis 1 ). Lisaks toob Trubetzkoy esile, et sugugi mitte kõikides keeltes ei loendata moorasid ühtmoodi. Ladina keeles on kinnised silbid kahemooralised, kuid näiteks lõunapaiuti keeles (jutoasteegi keelkond), kus rõhk on igal teisel mooral, on lühikese vokaaliga kinnised silbid ühemooralised

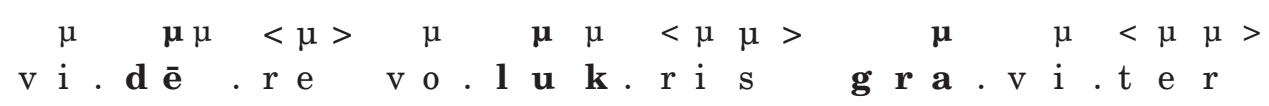

J o o n is 1. Rõhk klassikalises ladina keeles. 
ning ainult pika vokaali või diftongiga silbis on kaks moorat (Trubetzkoy 1939: 171).

Erinevalt Trubetzkoyst ei pidanud Leonard Bloomfield (1935: 110) moorat prosoodiliseks üksuseks, mis lisab silbile pikkust, vaid hoopis foneemi pikkuse relatiivseks mõõtühikuks: kui mingi keele lühike vokaal kestab ühe moora, siis sellesama keele pikk vokaal võib kesta näiteks poolteist või kaks moorat. Suuremat tähtsust mooradele Bloomfield ei omistanud.

Kuni möödunud sajandi lõpukümnenditeni jäigi moora kasutusse pigem mõõtühikuna. Probleem, mille lahendamiseks moora oli algselt mõeldud lühikeste ja pikkade silpide eristamine -, oli hõlpsalt selgitatav ka muul moel. Nimelt, pikk silp defineeriti kui hargneva riimiga või hargneva tuumaga silp (vt joonist 2; McCarthy 1979; Hayes 1981). Silbistruktuuri hierarhilisusest oli küll kirjutama hakatud mõnikümmend aastat varem (Pike, Pike 1947; Fudge 1969), aga niisuguste ideede arendamine ei olnud prioriteediks, sest Chomsky ning Halle fonoloogiateooria käsitles sõnu lineaarsete segmendijärjenditena ning toimis täielikult ilma silpidele või mis tahes muudele hierarhilistele üksustele viitavate reegliteta. Näis piisavat foneemi iseloomustavast tunnusest [ \pm silbiline] (lisaks tavapärastele tunnustele [ \pm konsonantne], [ \pm nasaalne], [ \pm madal] jt) (Chomsky, Halle 1968: 354).
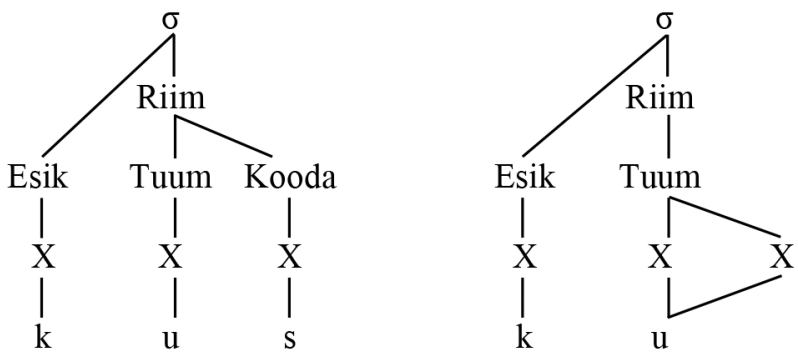

J o on is 2. Pikad silbid defineerituna silbiriimi või tuuma hargneva struktuuri kaudu. (Varem on kasutatud terminit silbialgus, kuid see tekitab segadust, kui on vaja kirjeldada vokaaliga algavaid silpe: tuleks öelda, et silbil puudub algus. Seetõttu teen ettepaneku kasutada silbistruktuuri ainsale kohustuslikule üksusele ehk tuumale eelneva positsiooni tähistamiseks terminit esik (ingl onset).)

Käsitlust, kus moora on pikkusühik, on hiljem edasi arendanud Anthony Fox (2000). Tema seisukoha järgi on moorade arv silpi iseloomustav omadus.

a. (Nespor, Vogel 1986, de Lacy 2007 jpt)

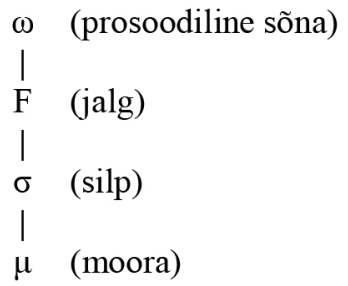

b. (Fox 2000)

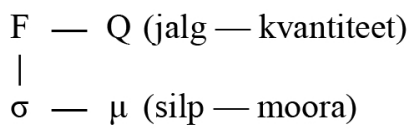

J o o n is 3. Võimalusi prosoodilise hierarhia esitamiseks. 
Sarnane omadus - kvantiteet - on ka jalgadel. Mooralisus ning kvantiteet moodustavad Foxi käsitluses sekundaarse hierarhia, mitte ei ole prosoodilised üksused, millest silbid ning jalad koosnevad, vt joonis 3b (Fox 2000: 108-111). Siiski möönab Fox, et mõnes keeles, nt jaapani keeles, võivad moorad olla ka prosoodilised üksused, nagu joonisel 3a (Fox 2000: 356). Tänapäeval levinuima teooria järgi ongi moora samasugune prosoodiline üksus nagu jalg ja silp, mitte pelgalt mõõtühik ega foneemi või silbi omadus.

\section{Tänapäevase teooria eelne moora eesti keele kirjelduses}

Kirjeldatud taustal on ootuspärane, et Ilse Lehiste, kes alustas oma uurijateed möödunud sajandi keskel, kasutas moorat foneemi pikkuse määratlejana, mitte iseseisva prosoodilise üksusena (vt Lehiste 1960, 1997). Lehiste käsitluses on eesti keele lühike häälik võrdne ühe, pikk kahe ja ülipikk kolme mooraga. Muidugi ei ole võimalik omistada moorale kui relatiivsele mõõtühikule mingit konkreetset väärtust millisekundites. Kõik ühemooralised häälikud ei ole sama absoluutse kestusega, näiteks lühike $h$ on umbes kolm korda lühem kui lühike $s$. Kuid moorade abil on lihtne kõrvutada mingi hääliku erinevaid suhtelisi pikkusi (Lehiste 1960).

Kui mõõta kõiki silbiriimi kuuluvaid häälikuid moorades, siis jõuab paratamatult järeldusele, et eesti keele teisevältelise sõna esisilp võib olla pikem kui kolmandavältelise sõna esisilp. Näiteks, lühim võimalik III-välte-

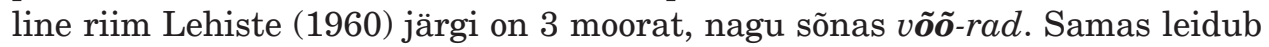
küllalt II-vältelisi sõnu, mille esisilbi riimis on 4 moorat, nt suurt-te. Niisiis oli selge, et häälikupikkustest ei saa otseselt tuletada väldet ega ka vastupidi. Kuna XX sajandi keskpaiga arusaam mooradest kui foneemipikkuse mõõtühikutest ei võimaldanud määratleda mingit konkreetset moorade arvu, millest algab kolmas välde silbi tasandil, tuli Lehistel välde defineerida kuidagi teisiti.

Lehiste leidiski, et välted on tajutavad silpide kestussuhete kaudu. Kestussuhteid ei arvutanud Lehiste aga mitte segmentide foneemilise pikkuse (st tema arusaama järgi moorade) kaudu, vaid nn foneemiliste silpide reaalselt mõõdetud kestuste kaudu. I vältes on rõhulise ja rõhutu silbi kestussuhe ligikaudu 2/3, II vältes 3/2 ning III vältes 2/1 (Lehiste 1960).

Lehiste foneetikuna ei läinud kaasa hilisemate moorateooria arengutega fonoloogias ega pidanud moorat eesti keele kirjeldamisel vajalikuks (vt kokkuvõtet Lehiste 1997). Tema seisukohti, sh ka arusaama moorast kui foneemipikkuse ühikust, pooldavad Eesti uuema põlvkonna foneetikudki (nt Lippus 2016: 121).

\section{Tänapäevane moorateooria}

Tänapäevases, Larry Hymani (1985), Hans-Henrich Hocki (1986), Bruce Hayesi (1989) jpt arendatud moorateoorias on moora universaalse prosoodilise struktuuri täieõiguslik liige, prosoodiline üksus, mitte mõõtühik. Moora on silbi moodustaja; vt joonist 4 , nii nagu silp on jala ning jalg prosoodilise sõna moodustaja (joonis 3a). 
Moora peamine ülesanne on eristada kergeid ja raskeid (varasemas terminoloogias pikki ja lühikesi) silpe. Silbi kaal on oluline väga paljude keelte rõhusüsteemide jaoks: rasked silbid tõmbavad rõhu enesele. Kergesse silpi kuulub ainult üks moora, raskes silbis on moorasid kaks, kuid silbi moorade arv ei tulene silbi koostises olevate foneemide arvust: esisilp sõnas tra.gi on kerge, sõnas ii.lid aga raske. Rohkem kui kaks moorat ei ole ühegi silbi koostises. See tähendab, et sugugi mitte kõik silbi häälikud ei saa olla mooradega seotud. Silbi tuum kui sonoorseim osa silbist on mooraga ühendatud, silbi esik aga mitte. Silbi esiku seondumatus omaette mooraga on põhjendatud sellega, et teadaolevalt ei leidu keeli, mille rõhusüsteem peaks $\mathrm{CV}(\mathrm{C})$-silpe rasketeks, aga $\mathrm{V}(\mathrm{C})$-silpe kergeteks, st silbi esik ei mõjuta silbi kaalu (Hyman 1985: 15). Koodakonsonantide seotus mooraga on keelespetsiifiline: mõnes keeles on CVC-silbid kerged (joonis 4a.ii), mõnes rasked (joonis 4b.i). Silbi koodat, mis ei ole mooraga ühenduses, võib nimetada ka silbilisandiks (ingl appendix). Sel juhul saab moora defineerida kui silbiriimi vahetu moodustaja (Zec 2007: 176).

a. Kerged silbid

i.

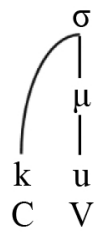

ii.

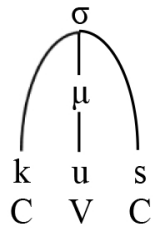

b. Rasked silbid i.

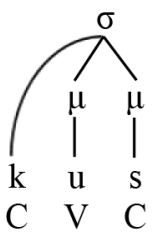

ii.

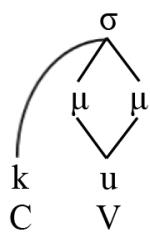

iii.

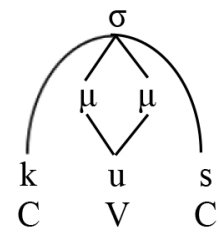

J o on is 4. Silbid moorateoorias.

Mooral kui prosoodilisel üksusel on kahtlemata ka teatav kestus. Seetõttu sõltub hääliku kestus silbis sellest, kas ja kui mitme mooraga on ta seotud. Moora lisamine muudab hääliku pikemaks ning seega võimaldab eristada lühikesi ja pikki vokaale (joonis 5) ning lühikesi ja pikki konsonante (joonis 6). Moora kestus võib siiski teatud piires varieeruda, just nagu varieerub silpide ja jalgade kestus - prosoodilise struktuuri kõik elemendid mõjutavad üksteist. a.<smiles>[AlH][AlH2]</smiles>

b.<smiles>[AlH][Tl]</smiles>

Joon is 5. Lühikesed ja pikad vokaalid. a.

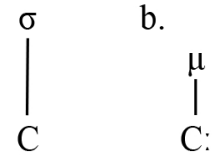

Joon is 6. Lühikesed ja pikad konsonandid.

Moorateooria suurimaks eeliseks peetakse seda, et just moorade abil on väga lihtsalt selgitatav, miks ning millistel tingimustel toimub eri keeltes asepikendus. Kui koodakonsonant kaob, tekkib vaba moora (joonis $7 \mathrm{~b}$ ), mis ühendub eelneva vokaaliga (joonis 7c). Selline pikenemine on aset leidnud näiteks ladina keeles: kasnus > cānus (Hayes 1989), aga ka eesti keeles: *mansikka > maasikas, *kansak> kaasa. 
a.

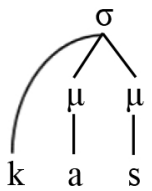

b.

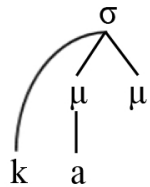

c.

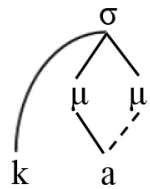

J o o n is 7. Asepikendus (Hayes 1989: 262 järgi).

Tuntud nähtus on ka pika vokaali lühenemine kinnises silbis, vrd nt türgi keele mõningaid vorme sõnast 'meetod': u.sul, u.su: lu, u.sul.den (silp su.'l pole võimalik). Kuna silbid on maksimaalselt kahemooralised, siis keeltes, kus koodakonsonandid seonduvad alati mooradega, peavad pika vokaaliga lahtised silbid lühenema, kui silbi lõppu sattub morfoloogiliselt oluline konsonant; vt joonis 8 (Zec 2007: 175).

a.

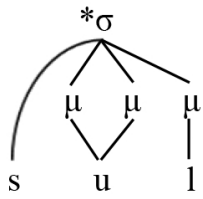

b.

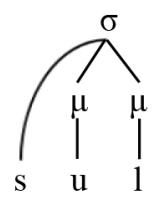

J o o n is 8. Liiga pika silbi lühenemine (CVVC $\rightarrow$ CVC).

Leidub ka keeli, kus CVVC probleem lahendatakse teise moora jagamise abil (joonis 9). Mõõtmistulemustega on kinnitatud, et moora jagamine muudab hääliku kestust: moorat jagav häälik on lühem kui tervet moorat hõlmav häälik ja moorat jagavate häälikute kestused sõltuvad teineteisest: ühe pikenedes teine lüheneb (Broselow jt 1997).

a.

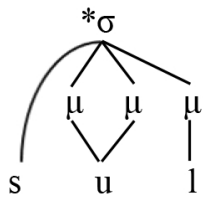

b.

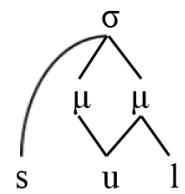

J o o n is 9. Liiga pika silbi lühenemine moora jagamise abil.

a.

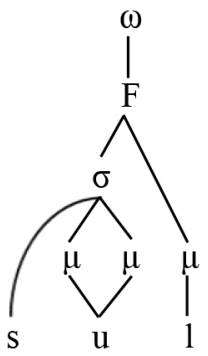

b.

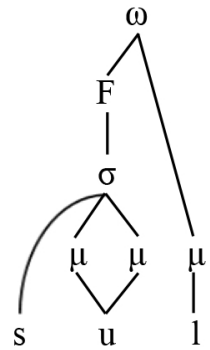

c.

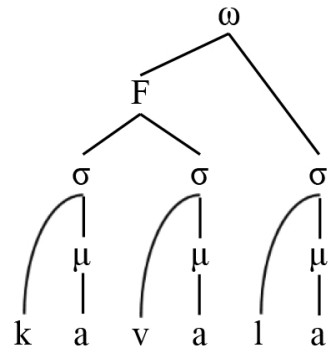

Joonis 10. Tasandite vahelejätmine. 
Üheks huvitavaks küsimuseks on seegi, kas iga moora peab kuuluma mõnesse silpi või leidub ka silbiväliseid moorasid, mis on ühendatud otse prosoodilise sõna või jalaga, nagu joonisel 10a ja 10b. Veelgi üldisemalt: kas prosoodiliste üksuste ühendamisel puusse tohib tasandeid vahele jätta? Õigupoolest ju silbi esiku ning lisandite puhul jäetakse vahele mooratasand ning üsna tavaline on ka jalatasandi vahelejätmine. Jalg koosneb vähemalt kahest moorast, aga mitte rohkem kui kahest silbist (Hayes 1995: 71), seega CV.CV.CV-sõnas jääb üks silp paratamatult jalaväliseks, vt joonist 10c. Tasandite vahelejätmise lubatavuse üle on arutlenud näiteks Junko Itō ja Armin Mester (2003), Paul Kiparsky (2003), Bert Vaux ja Andrew Wolfe (2009). Valitseb seisukoht, et taolised otseühendused on võimalikud ainult üksuste servas, mitte keskel, ning et kõik üksused peavad olema ühendatud puu juurega.

Tasandite vahelejätmine võib mõnes keeles olla koguni nii ekstreemne, et mõne tasandi prosoodilisi üksusi üldse ei moodustatagi. Näiteks gokana

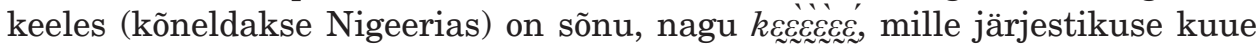
nasaleeritud $\varepsilon$ jaotamine silpideks tekitaks vaid tarbetuid lisaküsimusi (mitu $\varepsilon$-d on ühes silbis jmt). Ükski gokana fonoloogiline ega morfoloogiline protsess ei sõltu silpidest, küll aga on olulised moorad (Hyman 2008: 113). Samamoodi on keeli, kus pole vaja moorasid. Niisugustes keeltes puudub häälikute pikkuskontrast ja rõhusüsteem toimib põhimõttel „silp on silp”. On ilmne, et eesti keel nendele tingimustele ei vasta.

Kui lubada jalatasandi vahelejätmist ainult prosoodilise sõna alguses või lõpus, tekkib probleem keeltega, kus rõhk paikneb igal kolmandal silbil: eesti keeleski võimaliku häälduse $k a \cdot$ vva.la.mat:.te.le korral jääb jalaväline silp sõna keskele. Nii pikad sõnad on alati morfoloogiliselt komplekssed. Seega saab väita, et jalatasand jääb vahele ikkagi üksuste piiril, eesti keeles näiteks tüve lõpus. Osa autoreid kasutab ka rekursiivselt moodustuvaid jalgu, luues nii silla rekursiivsete süntaksistruktuuride ja mitterekursiivsete madalama tasandi fonoloogiliste struktuuride vahele (nt Kager, Martínez-Paricio 2018).

Teoreetilised vaidlused universaalse prosoodilise struktuuri üle jätkuvad. Ka mooradega seoses on mitmeid täpsustamist ootavaid küsimusi: kuidas tekkivad sõna algusesse geminaadid, milliseid moorasid tohib kahe segmendi vahel jagada, kas silbis on peamoora ja kõrvalmoora või on moorad ühesuguse prominentsusega jpm. Enamik uurijaid on üksmeelel järgnevas.

1. Kõik segmendid on läbi kõrgemate tasandite üksuste (moora, silp, jalg) ühendatud prosoodilise puu juurega (prosoodilise sõnaga), kusjuures ühendusjooned ei lähe risti.

2. Tasandite vahelejätmine prosoodilises puus on lubatud ainult üksuste piiril.

3. Jalg on minimaalselt kahemooraline ja maksimaalselt kahesilbiline.

4. Silp on maksimaalselt kahemooraline.

5. Kui võimalik, siis silp algab konsonandiga. Alguskonsonant ei ole seotud omaette mooraga.

6. Silbi kooda seotus mooraga on keelespetsiifiline.

7. Lühike vokaal on ühemooraline, pikk kahemooraline; lühike konsonant on ilma moorata, pikk ühemooraline.

8. Moorasid võib (teatud keelespetsiifilistel tingimustel) jagada mitme hääliku vahel. 


\section{Moora leiukohad eesti keeles}

\subsection{Transkriptsioonist}

Kuna siinse artikli põhitähelepanu on pikkuskontrastidel, siis pole põhjust häälikute kvaliteeti väga täpselt märkida. Kasutan eesti kirjakeele tähestikku, ainult $g, b$ ja $d$ asemel on $k, p$ ja $t$. Keeleajaloo näidetes, kus see on oluline, märgib klusiili nõrgenemist kaareke tähe kohal, nt *patan > paja.

Pikkuskontrastid tulenevad prosoodilisest struktuurist. Hierarhilise struktuuri esitamine lineaarsena ei ole lihtne ülesanne ning osa infot läheb paratamatult kaduma. Samas ei ole otstarbekas struktuuri alati täielikult välja joonistada. Siinses artiklis on silbipiirid vajadusel märgitud punktidega ning jalad eristatud ümarsulgudega, nagu ongi fonoloogiakirjanduses tavaks. Näiteks, (ka.va).la vastab struktuurile joonisel 10c.

Fonoloogiliselt oluliste pikkuserinevuste markeerimiseks kasutan rahvusvahelise foneetilise tähestiku pikendusmärke : (pikk) ja ' (poolpikk). Kuna kirjeldatavas teoorias on pikkus otseselt seotud mooraga, siis võib ka öelda, et : tähistab mooraga seotud konsonanti ning kahe mooraga seotud vokaali. Poolpikkuse märgiga - tähistan jala viimase moora pikenemist. Pikkuskontrastid, mis ei erista tähendusi, jäävad märkimata.

Ka geminaadid on üldjuhul esitatud pikendusmärkide, mitte topelttähtede abil. Topelttähti kasutan geminaatides ainult siis, kui on vaja tähistada silbivõi jalapiiri geminaadi sees, nt /ut:"e/ ehk /(ut"*).te/ (tavaortograafias utte). Häälduses on siiski tegemist ühe pika häälikuga, mitte identsete häälikute järjendiga. Silbipiiri märkimine pikendusmärgi ette ei oleks õige, sest pikeneb just nimelt silbi kooda, mitte esik.

Näitesõnad on transkriptsioonis (kaldkriipsude vahel) ainult siis, kui see on vajalik. Kõik muud näited esitan tavaortograafias. Mõnel juhul on otstarbekas näidata silbi- ning jalapiire ka tavaortograafias.

\subsection{Kolm väldet}

Eesti keele kolme välte süsteemi esitamine moorateoorias näib lahendamatu probleem, kui eeldada, et silbis on maksimaalselt kaks moorat. Nii on võimalik eristada lühikesi ja pikki üksusi, kuid mitte lühikesi, pikki ja ülipikki. Enamikus moorateoreetilistes vältekirjeldustes on seetõttu loobutud ühest või teisest 3. peatüki lõpus välja toodud põhimõttest. Näiteks Patrik Bye (1997) jätab III välte jaoks tarviliku lisamoora puu juurega ühendamata ning lubab kolmemooralisi vokaale; Martin Ehala (2003: 73-75) lubab ühemooralisi pikki vokaale ning vajab seetõttu lisatasandit prosoodilises struktuuris; Arvo Eek ja Einar Meister (2004) esitavad pika vokaali kahe identse segmendi järjendina, et saaks välteerinevusi järjekindlalt seletada moorade jagamise abil. Teooria täiendused iseenesest ei ole halvad, kuni struktuuripuud ei lähe liiga keerukaks ega keelespetsiifiliseks, ent nimetatud vältekäsitlused ei ole piisavalt heas kooskõlas foneetiliste mõotmistulemustega (vt Prillop 2015).

Küllap teoreetilised raskused sobitada moorateooria nõuetele vastav prosoodiline struktuur foneetiliste faktidega ongi viinud foneetikud tõdemuseni, 
et moora eesti keelde ei sobi: väldete fonoloogilisel kirjeldamisel peetakse peamiseks silpide kestussuhteid kahesilbilistes jalgades (Lippus 2016: 134), isegi kui leitakse foneetilisi tõendeid moorade olemasolust ja ühesilbilistest jalgadest (nt Türk jt 2017).

Silpide kestussuhetele tuginev vältekirjeldus pole kindlasti mitte ideaalne. Liisi Piits ja Mari-Liis Kalvik (2017) on leidnud, et mõne sõna puhul ei lange kokku kestussuhte järgi arvutatud välde ning kuulaja hinnang vältele. Näiteks sõna maitsekas tundub kuulajale II-vältelisena isegi siis, kui esimene silp on teisest enam kui 4 korda suurema kestusega, ning sõna kaine III-vältelisena, kuigi silpide kestussuhe on II vältele iseloomulikult 1,5 (Piits, Kalvik 2017: 131).

Kestussuhted ei kehti ka sõnades, mille esisilbis on väga palju erinevaid häälikuid. Eesti keele spontaanse kõne foneetilisest korpusest ${ }^{1}$ otsitud II-vältelised juurte, noorte ja suurte annavad keskmiseks kestussuhteks 2,9 (kokku 12 näidet), mis paigutab need hoopis III vältes sõnade hulka. Samamoodi võib arvata, et kestussuhted ei klapi tegeliku vältega ka sellistes sõnades, kus rõhutus silbis on palju häälikuid (võtaks, napilt jt). Korrektse II välte kestussuhte jaoks peaks juurte, noorte ja suurte puhul arvutustest välja jätma esimese silbi koodakonsonandid $r$ ja $t$. Nii aga on lõpuks ikkagi vaja mingisugust hierarhilist struktuuri, mis põhjendaks, milliseid häälikuid või nende osi kestussuhete arvutamisel arvesse võtta ei tohi. Kuulaja jaoks on eriti keeruline olukord geminaatides: silbisuhete arvutamisel tuleks välja jätta see osa geminaadist, mis kuulub rõhutu silbi esikusse, teatud juhtudel ka väidetavasse silbilisandisse jääv osa (nt rüt<t>.mi, vt Eek, Meister 2004: 267), kuid mingit akustiliselt selgelt määratavat piiri nende osade eristamiseks ei ole.

Lisaks tekitavad probleeme III-vältelised sõnad, mille teine silp on kahemooraline, nt hambaid, mõtteid, seadmeid. Pole päris selge, kas järgsilp nendes vormides peab olema kaasrõhuline: eesti keele spontaanse kõne foneetilisest korpusest leitud mõte-tüüpi sõnade mitmuse osastava vormides oli vaid ühel juhul 18-st märgitud teine silp kaasrõhuliseks. Kui oletada, et neis sõnades kuulub teine silp esimesega samasse jalga, siis tuleks neid sõnu silpide kestussuhete põhjal pidada II-vältelisteks (teine, diftongi sisaldav silp ei ole vähemalt kaks korda lühema kestusega kui esimene, nagu oleks vaja III välte tuvastamiseks) ${ }^{2}$. Kui aga oletada, et neis sõnades on teine silp kaasrõhuline, st esisilp moodustab üksi omaette jala, pole kestussuhteid arvutada ja seega ka väldet määrata üldse võimalikki.

Just sellised sõnad nagu hambaid ning nende ajalooline areng annavad hea vihje, kuidas selgitada III välte erilisust. Ajalooliselt on tegemist konsonanttüvelise sõnaga, millest mitmuse osastav moodustus kujul *(ham.pa).(si.ta) > *(ham.pa).(hi.ta). Pärast vokaalidevahelise *h kadu tekkis diftongiga, s.o kahemooraline järgsilp, mis tundus kaasrõhulisena: *(ham).(pai.ta). Esisilp moodustas omaette jala, olles seega erinev nimetava vormist (ham.mas).

Samasugune kahe rõhulise silbi järjend kujunes veidi hiljem paljudes

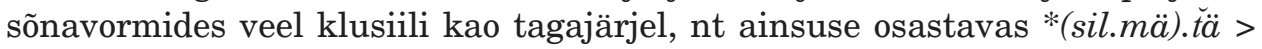

\footnotetext{
${ }^{1}$ http://www.keel.ut.ee/et/foneetikakorpus (25. VIII 2017).

${ }^{2}$ Eesti keele spontaanse kõne foneetilisest korpusest leitud 18 sõnavormi põhjal on rõhulise ja rõhuta silbi keskmine kestuste suhe sellise struktuuriga sõnades 1,34; standardhälve 0,32 (25. VIII 2017).
} 
*(sil).(mää) > (sil).ma. Sarnast arenguteed on varem oletanud ka Arvo Eek ja Toomas Help (1986: 19). Võimalik, et juba oli hakanud välja kujunema ka jala lõpupikenemisena tuntud nähtus. ${ }^{3}$ Hiljem vormusid ühesilbilised jalad veel sisekao tagajärjel, nt *(lau.la).(ma.hen) $>$ *(laul).(maan) > (laul).ma, ja

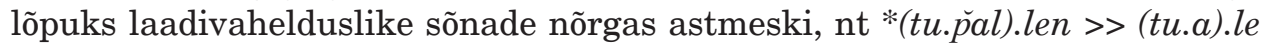
$>$ (toa).le. Tähendusi eristavat rolli erinevatel jalastruktuuridel päris alguses muidugi veel polnud. Fonoloogiline vältevastandus sai kujuneda alles pärast järgsilbi vokaalide lühenemist ning mõningate sõnalõpuliste konsonantide kadu, kui erinev jalastruktuur oli muutunud teatud sõnavormide ainsaks eri-

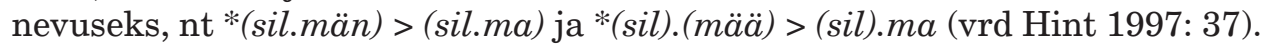

Kolmandas vältes on tänapäeval sõnad, mille teises silbis oli kunagi lühike lahtine vokaal, nt *sil.mä > silm, *lau.la.nut > laulnud, *tüt.tä.ren > tütre. See on andnud alust näha vokaalikadusid vältevahelduse otsese põhjustajana (esimesena Weske 1879: 7-8). Vokaalikaod ja eelneva silbi pikenemine on omavahel tihedalt seotud teisteski keeltes, nt /talə/ > /ta:l/ 'lugu' inglise või /borv/ $>$ /bo:r/ 'mets' serbohorvaadi keele ajaloos (Hayes 1989: 266-267; Kavitskaya 2002: 102). Enamasti on seda põhjendatud moorade arvu säilitamisega jalas. Päris kindlaid asepikenduse näiteid leidub siiski ainult lühikeste silpide kohta (st CV.CV > CV:C). Kui samamoodi pikeneks kahemooralise silbi vokaal, tekkiks ebasoovitav kolmemooraline silp (nt *lau.la.nut $>$ **lauul.nut).

Rõhutute vokaalide redutseerumine on keeltes niisama loomulik nagu assimilatsiooninähtused (vt nt Crosswhite 2004). Ühelt poolt laseb rõhutu silbi väiksema intensiivsusega ja lühemalt hääldatud vokaal tajuda eelnevat silpi suhteliselt pikemana; teiselt poolt jätab pikemalt ja intensiivsemalt hääldatud rõhuline vokaal järgneva rõhuta silbi hääldamiseks vähem energiat. Kui redutseerumine on küllalt kaugele arenenud, võidakse senised (CVX.Cə)struktuurid ümber tõlgendada (CVX).Cə-struktuurideks (nt *(tüt).tə.ren, *(õp).pi.nut). Sellisele ümbertõlgendusele aitab küllap kaasa, kui keeles on ühesilbilised pearõhulised jalad juba varasemalt olemas, nagu eesti keeles oligi.

CV.CV-sõna ei saa niisama lihtsalt muutuda (CV).Cə-sõnaks, sest ühemooralised jalad pole võimalikud. Seepärast näibki toimuvat asepikendus, et omaette jalga paigutuv CV-silp muuta raskeks: (CV.CV) > (CV:). $\mathrm{C}$ ə > (CV:C). Eesti keeles lühikese vokaali pikenemist ei toimunud, sest see oleks hävitanud leksikaalsed kontrastid.

Alan Prince esitas juba 1980. aastal käsitluse, mille kohaselt sõna on III vältes, juhul kui rõhuline silp moodustab omaette jala, ning II vältes, kui jalas on koos rõhuline ja rõhuta silp. Lisatunnusena aitab II ja III väldet eristada jala lõpupikenemine, mis III vältes muudab rõhulise silbi koodas olevad häälikud ülipikaks. Nii on ühtsesse teooriasse seotud nii välted kui ka CVCVsõnade poolpikk teise silbi vokaal (Prince 1980). Prince kasutas väldete kirjeldamisel varast meetrilist fonoloogiat. Joonisel 11 on esitatud erinevas vältes sõnade prosoodilised struktuurid tänapäevases moorateoorias. I väldet eristab II ja III vältest esisilbi struktuur, III väldet I-st ja II-st aga jala struktuur (Prillop 2013: 16).

Samamoodi nagu näidatud joonisel 11, saab jala struktuuri abil eristada II ja III väldet ka sõnades, kus esimese ja teise silbi piiril on konsonantühend;

${ }^{3}$ Sarnane fenomen - teise moora pikenemine - ilmneb ka soome keeles (Suomi jt 2008: 91). 
vt joonist 12. Niisama hästi võib aga II-vältelise sõna esisilp konsonantühendiga sõnades olla ühemooraline (seepärast ongi kooda moora joonisel sulgudes). Ühest küljest ei erista sonoorsete konsonantide mooralisus sellises positsioonis tähendusi, silbilõpu moora pole leksikaalne: /(kül.ma) $/=/($ kül ¿.ma $) /$. Teisest küljest hoiaks moora lisamine tüvevariandid sarnasemad. (II-vältelise jala esisilpi kirjeldab ühemooralisena Ehala (1999: 462), aga tema peab võimalikuks ka pika vokaaliga silpide ühemooralisust.)
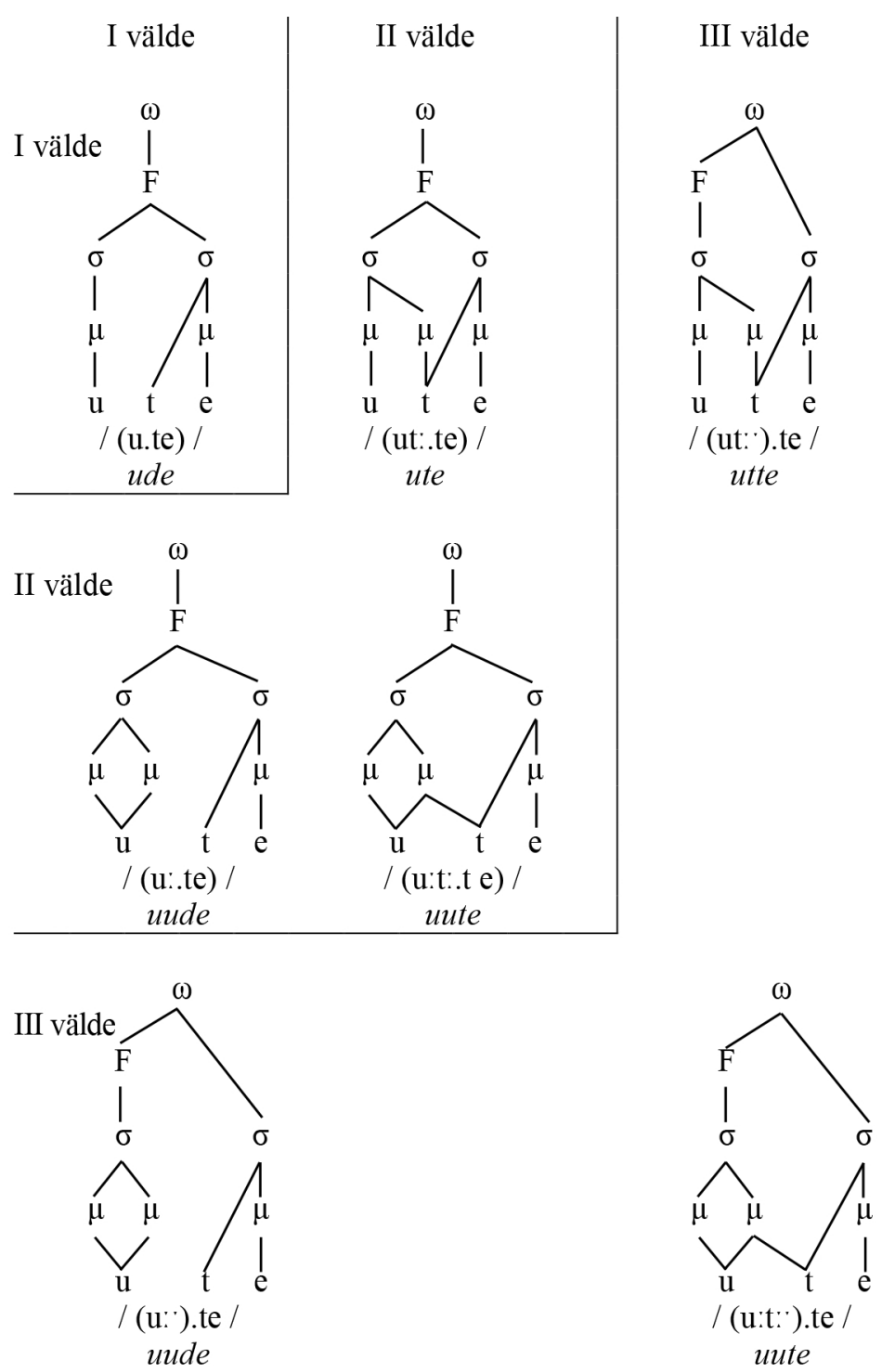

J o on is 11. Eesti välted (Prillop 2013: 16; muudetud on näitesõnade transkriptsiooni). 
a. II välde

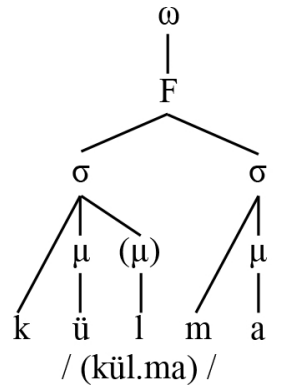

b. III välde

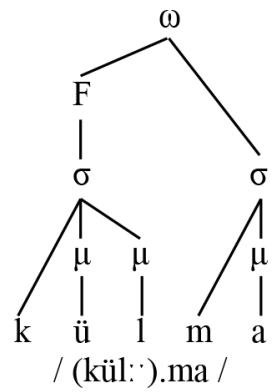

J o o n is 12. Eesti välted konsonantühendiga sõnades.

Joonisel 11 esitatud skeemid on heas vastavuses foneetiliste mõõtmistega. Silpide kestussuhete arvestamiseks võrdsustan jalasisese moora kestuse 1-ga ning jalalõpu pikenenud moora kestuse 1,5-ga. Joonistel esitatud struktuuride põhjal saame seega järgmised silbiriimide kestussuhted: I vältes $2 / 3 \approx 0,67$ $(1 \mu / 1,5 \mu)$, II vältes $4 / 3 \approx 1,33(2 \mu / 1,5 \mu)$ ning III vältes $5 / 2=2,5(2,5 \mu / 1 \mu)$. Tegelikkuses mõjutavad kestussuhteid ka häälikute omakestused ning esisilbi kooda struktuur. Igal juhul on moorade järgi arvestatud kestussuhted küllalt heas kooskõlas tegelike mõõtmistulemustega, mis I välte puhul on jäänud vahemikku 0,5-0,8; II välte puhul 1,2-2,3; III välte puhul 2,0-3,9 (vt erinevate autorite tulemusi koondavat tabelit Lippus 2016: 136).

Esitatud skeemid sobivad ka väldetele iseloomulike põhitoonimuutustega. Põhitoon on seotud jalaga: jala alguses põhitoon ei muutu või tõuseb, jala lõpus aga langeb. Sel moel aitab toonikontuur eristada erineva struktuuriga jalgu: III välte sõnades algab langus esisilbi keskel ning teine silp öeldakse madala tooniga, II ja I vältes algab langus esisilbi lõpus ning kestab teise silbi lõpuni (andmed toonimuutuste kohta Lippus 2016: 141; Asu 2016: 169). Kõigil kolmel juhul on pöördepunkt jala keskel. Võimalik, et põhitooni muutumist saab siduda ka otseselt mooradega (vt joonist 13): jala esimene moora on seotud kõrge tooniga $(\mathrm{H}$, high), mis laieneb ka järgnevatele mooradele samas jalas, kuid jala lõpus peab toon olema langenud madalaks (L, low), mistõttu viimane moora on langeva tooniga $(\mathrm{HL})$. Kui sõnas on veel tooniga sidumata moora-
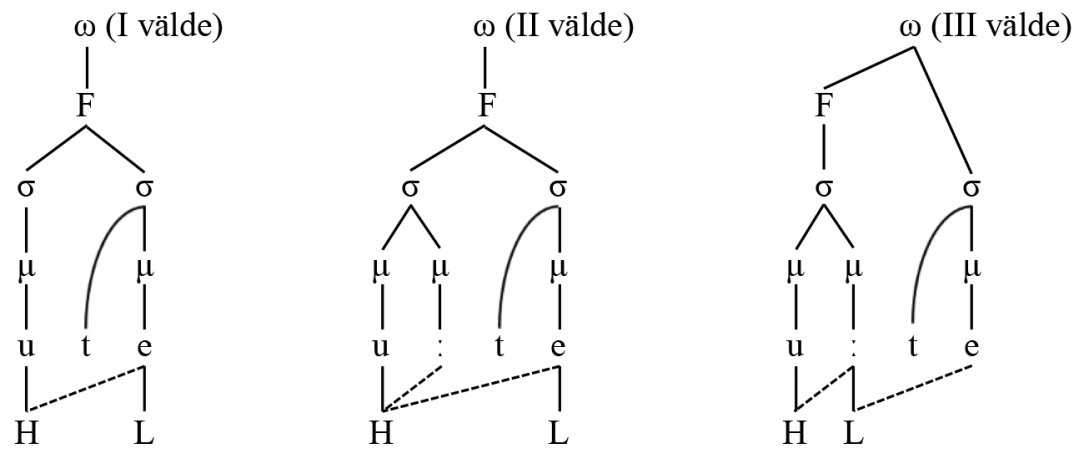

Joon is 13. Põhitooni oletatav seos mooradega. 
sid, laieneb neile eelneva moora madal toon. Mitmetes keeltes on just moora (mitte silp) see prosoodiline üksus, millele saab omistada tooni (Yip 2007: 237).

Viimasel ajal on hakatud mitmetes Euroopa keeltes esinevaid tooniaktsente kirjeldama sõna prosoodilisest struktuurist tuleneva nähtusena. Sellises käsitluses ei ole tarvis sõnadele omistada leksikaalseid toone, sest toonid on determineeritud prosoodiliste üksuste järgi. Näiteks Bruce Morén-Duolljá (2013) rootsi keele tooniaktsentide analüüs näitab, et toonid markeerivad üksuste piire; Björn Köhnlein (2016) demonstreerib, et frangi keeles eristavad toonid erineva struktuuriga jalgu. Ka taani ja liivi stød'i (katketooni) on seotud jala struktuuri ning mooradega (Kiparsky 2017). Usutavasti aitavad edasised uuringud paremini selgitada, mis osas on Läänemere areaali keelte prosoodilised struktuurid ning nende struktuuride poolt määratud toonid sarnased.

III välte struktuuridega, kus teine silp jääb jalaväliseks, saab põhjendada ka teise silbi vokaali redutseerumist. Ning lõpuks, kui omaette jalga paigutuv silp on defineeritud kui III välde, on seletatud seegi, miks ainult III vältes sõnade kaasrõhk võib vahetult järgneda esisilbile.

Kõik nimetatud hääldusnüansid, aga kindlasti ka kontekst, kus sõna kasutatakse, aitavad kuulajal taasluua välte määramiseks vajaliku struktuuri, millega kõneleja produtseeritud häälikujärjend kõige paremini sobib. Oluline on tajuda jala lõppu, mida markeerivad pikenenud häälikud ning tooni langus. Välteid eristavad kestussuhted küll eksisteerivad (vähemalt CV(X).CV struktuuriga sõnades), kuid need ei saa olla kõne mõistmisel primaarsed.

\subsection{Leenis ja fortis}

Eesti keeles on tavaks rääkida nõrkadest ehk leenisklusiilidest (ortograafias g, $b, d$ ) ja tugevatest ehk fortisklusiilidest (ortograafias $k / k k, p / p p, t / t t$ ). Leenis $v s$. fortis eristab tähendusi sõnades, nagu kood - koot, tibu - tipu, ladva - latva. Samas ei peeta leenis- ja fortisklusiile erinevateks foneemideks. Lühikesed klusiilid sonoorses ümbruses on leenised, ülejäänud klusiilid on fortised. Rahvusvahelistes eesti keele tutvustustes ongi eelistatud vastandust pikk-lühike (nt Asu, Teras 2009), mis moorateoorias võiks tähendada lihtsalt mooraga seotud ja mooraga sidumata konsonantide vastandust. Moora lisab konsonandile nii kestust kui ka intensiivsust, sobides seega hästi eesti keele fortiseid ja leeniseid eristama.

Leenis- ja fortisklusiilide problemaatikat eesti keeles on pikemalt käsitlenud Eek ja Meister (2004). Ka nemad jõuavad järeldusele, et ei ole otstarbekas tõlgendada lühikesi ja pikki klusiile (ega üldisemalt obstruente) vastavalt leenis- ja fortisfoneemidena; piisab vastandusest pikk vs. lühike. Kuigi Eek ja Meister lähtuvad nüüdisaegsest moorateooriast, defineerivad nad fortise kui kahe ühesuguse foneemi järjendi, mitte kui mooraga seotud klusiili: nt ortograafiline tipu on neil fonoloogiliselt /tippu/, mitte /tip:u/ (Eek, Meister 2004: 257-259). Selline tõlgendus on vajalik Eegi ja Meistri väljapakutud välteteooria jaoks, kus välteid eristatakse naaberhäälikute kestussuhete järgi. Hääldusest tulenevat põhjendust fortistele kui topeltobstruentidele aga pole. Eesti keele geminaatide uurimisel ei ole leitud selgeid tõendeid, et toimuks regulaarne topeltartikulatsioon, st geminaadid on pigem pikad häälikud ning 
hääldusorganid ei korda geminaatide hääldamisel sama liigutust kaks korda, nagu peaks olema topeltkonsonandi puhul (Lippus 2016: 136-137).

Eegi ja Meistri käsitlus tekitab ka silbipiiri probleemi. Praeguseks küllap juba üldtunnustatud seisukoha järgi on eesti keele üksikklusiil mittesonoorses ümbruses tajutav fortisena (nt katse), sonoorses ümbruses aga leenisena (nt kandi) (vt Teras 2016: 66). Seega, iga klusiil, mis paikneb sonoorses ümbruses ja on tajutav fortisena, peab Eegi ja Meistri käsitlusest lähtuvalt olema fonoloogiliselt kahe klusiili järjend, nt rütmi $=/$ rüttmi/, nitro = /nittro/, sest muidu tajutaks teda leenisena (Eek, Meister 2004: 265). Niisugune tõlgendus läheb vastuollu universaalse printsiibiga, mis keelab morfeemisisesed kõrvutised identsed segmendid (obligatory contour principle; vt McCarthy 1986) ning tekitab probleeme ka silbipiiri määramisel, kuivõrd silbipiir peaks paiknema geminaatkonsonandi sees. Silbitamine /rüt.tmi/ on küll teoreetiliselt võimalik (sonoorsus tõuseb silbituuma suunas), aga ei sobi põhimõttega, et silbialguse konsonantühendid peavad keeles esinema ka sõnaalgulistena. Silbitamisprobleemi vältimiseks esitavad Eek ja Meister ka alternatiivse tõlgendusvõimaluse, mille järgi niisuguste topeltkonsonantide teine osis ei kuulu mitte järgnevasse silpi, vaid silbilisandisse (joonis 14), kuid jätavad küsimuse lõpuks siiski lahtiseks, sest nende esitatud vältekirjelduse jaoks pole see oluline: ei silbilisand ega esik ei osale vältevastanduses. Samuti ei esita nad oma uurimuse teoreetilises osas sõnasisese silbilisandi moorateoreetilist kirjeldust ega vastavaid jooniseid (Eek, Meister 2004: 266-267, 337-342).

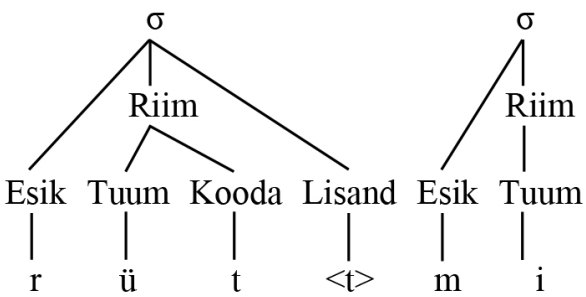

Joonis 14. Topeltkonsonandi teine osis silbilisandina (Eek, Meister 2004: 261262).

Kui lähtuda eespool mainitud lihtsaimast võimalusest, mida pakub tänapäevane moorateooria, et fortisklusiil on mooraga seotud ja leenisklusiil mooraga sidumata, siis silbitamisprobleemi ei tekki, sest pole mingit põhjust tõlgendada fortiseid helilises ümbruses alati topeltklusiilidena. Geminaat on moorateoorias küll defineeritud kui mooraga seotud konsonant, kuid see ei tähenda, et mooraga seotud konsonant peaks jagunema kahe silbi vahel mis tahes häälikulises ümbruses. Leksikonis mooraga seotud konsonandist saab pindstruktuuris geminaat ainult siis, kui järgnev silp jääks muidu ilma esikuta. Näiteks sõnas tipu on $p$ leksikonis mooraga seotud (muidu oleksid tipu ja tibu eristamatud), vt joonist 15a. Pindtasandi prosoodilise struktuuri loomisel moodustatakse kõigepealt silbid (kuna silbistruktuur on reeglipäraselt genereeritav, pole tarvidust seda leksikonis valmis kujul hoida). Esmalt paigutatakse moorad silpidesse, vt joonist $15 \mathrm{~b}$. Klusiili moorat ei ole võimalik lisada mujale kui esimesse silpi, sest kui lisada see teise silbi algusesse, 
tekiks mooraga seotud esik, mis on aga universaalselt keelatud. Järgmiseks ühendatakse konsonandid, arvestades et võimalusel on igal silbil esik (seegi on kõigis keeltes kehtiv nõue). Seetõttu moodustubki geminaat, et sõna teine silp ei jääks ilma esikuta, vt joonist 15c. (Niisuguse geminaatide kirjelduse esitas Bruce Hayes 1989: 257-258.) Samamoodi luuakse geminaat ka siis, kui mooraga seotud klusiil järgneb sonoorsele konsonandile; vt joonist 16. Kui aga sonoorne konsonant järgneb mooraga seotud klusiilile, saab sellest konsonandist järgsilbi esik ning ei ole ühtegi mehhanismi, mis jagaks mooraga seotud klusiili sellises positsioonis kahe silbi vahel; vt joonist 17.

a.

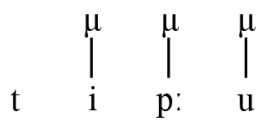

b.

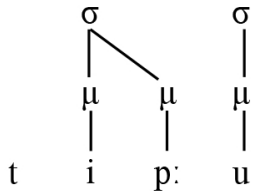

c.

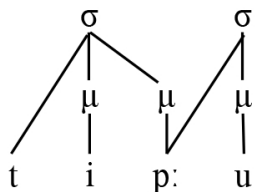

J o o n is 15. /tip:u/ silbistruktuuri moodustumine.

a.

b.

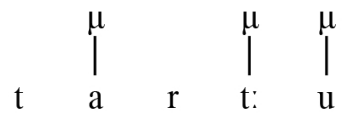

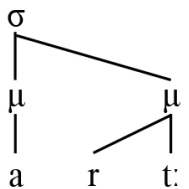

c.

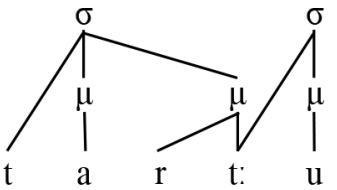

Jo on is 16. /tart:"u/ silbistruktuuri moodustumine.

a.

b.<smiles>I[AlH]I</smiles>

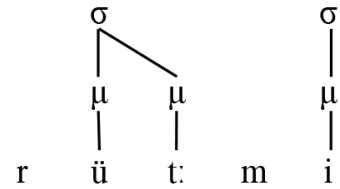

c.

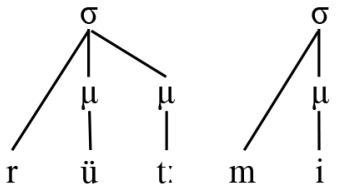

J o on is 17 . /rüt:mi/ silbistruktuuri moodustumine.

Kirjeldades leeniseid kui mooraga sidumata ning fortiseid kui mooraga seotud klusiile, on hõlpus põhjendada, miks eesti keeles pole võimalikud niisugused ühesilbilised sisusõnad, kus lühikesele vokaalile järgneb vaid $g, b$ või $d$. Eesti keele sõna peab olema vähemalt kahemooraline, kuid näiteks sõnas sag oleks ainult üks moora. Moora lisamisel saaksime sellest kas sõna saag, $s a k k$ või saak, mis kõik on ka kasutuses; vt joonist 18. Samuti ei ole eesti keeles joonisel 18a kujutatud struktuuriga III-välteliste sõnade algussilpe - III vältes sõna esisilp moodustab omaette jala, aga jalas peab olema kaks moorat. Moora lisamine leksikaalselt mooraga sidumata klusiilile on eesti keeles keelatud, sest see muudaks sõna tähendust. 
a.

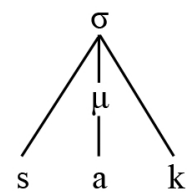

b.

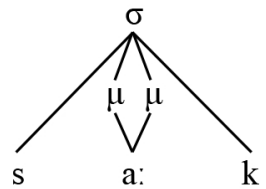

c.

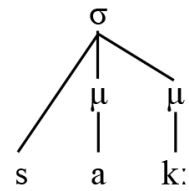

d.

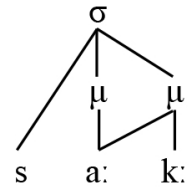

J o o n is 18. Silbid sag, saag, sakk ja saak.

Mõneti problemaatilisem on mooraga seotud klusiil väga pika silbi lõpus, nt sõnades kaart ja väärt. Kui selline klusiil jääb jala lõppu, saab tema ühendamisel prosoodilisse puustruktuuri silbitasandi vahele jätta; vt joonist 19a. Jala sees (nt vormides kaarte, keelte) teiseneb leksikaalselt mooraga seotud klusiil pindstruktuuris lühikeseks, mooraga sidumata geminaadiks; vt joonist 19b. Kolmandat moorat II-vältelise sõna esisilpi lisada ei saa, kuna nii tasandite vahelejätmine prosoodilises puus kui ka moora jagamine on lubatud vaid üksuste servas. Kahjuks puuduvad joonisel 19 esitatud struktuuriga sõnade kohta täpsed võrdlevad mõõtmistulemused, mis esitatud tõlgendust kas kinnitaksid või selle ümber lükkaksid. Ometi just nende sõnade analüüs oleks põnev ka üldteoreetiliselt.
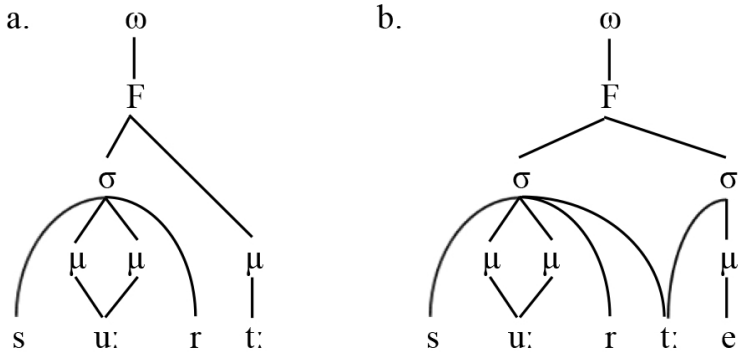

J o o n is 19. Sõnade suurt ja suurte struktuur.

Üks huvitav küsimus tekkib ka seoses sõnadega, kus esisilbi lõpus on mooraga sidumata klusiil, nt pudru, ludri, ladva. Kuna nende esisilp on ühemooraline, peaks siin esitatud seisukohtade järgi tegu olema I vältes sõnadega, just nagu padi või ladu. Juba vähemalt pool sajandit on viidatud võimalusele, et neid sõnu silbitatakse nõnda, et esimene silp lõppeb vokaaliga ning teise silbi algusesse jääb konsonantühend (Hallap 1963: 117 jj; Raun, Saareste 1965: 11). Sarnaselt ei saa aga silbitada ku.tsa, mu.tri või ra.sva, kuigi ei tekiks vastuolu universaalse nõudega, et sonoorsus peab suurenema silbi tuuma suunas, ning vähemalt mõned neist konsonantühendeist on ka sõna alguses (võõrsõnades) võimalikud. Loomulikuna tunduv silbitamine $p u . d r u$ kinnitab selliste sõnade tajumist I-vältelistena. Samas ei kaota see vajadust eristada silbi lõpus leeniseid ja fortiseid, sest sõna lõpus on kontrast ikka olemas (vrd saag ja saak). 


\section{Kokkuvõte}

Tänapäevase fonoloogiateooria järgi on häälikute erinev pikkus seotud hierarhilise prosoodilise struktuuriga. Enam ei räägita pikkadest ja lühikestest foneemidest (vähemalt juhul, kui nende foneemide muud omadused on ühesugused), vaid sellest, kas ja kui mitme mooraga on foneem seotud. Moora on prosoodiline üksus, mis kuulub silpi. Silbid omakorda kuuluvad jalgadesse. Kui mingi keel eristab pikki ja lühikesi häälikuid, siis on selle keele tänapäevases fonoloogilises kirjelduses vaja moorasid (või mingeid muid struktuuriüksusi silbitasandi ja foneemitasandi vahel).

Ka silbilõpu konsonant võib olla mooraga seotud. Kui mooraga seotud konsonandile järgneb vokaal, siis see konsonant gemineerub. Nii on näiteks eesti keele sõnades tipu ja ärtu. Sõnas rütmi on küll mooraga seotud klusiil, kuid see ei jagune kahe silbi vahel, sest klusiilile järgneb konsonant, mitte vokaal. Sel moel saab eristada silbilõpu leenis- ja fortisklusiile: leenised ei ole mooraga seotud, aga fortised on. Varasemalt on fortiseid kirjeldatud kui kahe identse klusiili järjendeid, kuid see tekitab vastuolu vähemalt kahe universaalse põhimõttega: vältida tuleks identsete segmentide järjendeid ühe morfeemi piires ning selliseid silbialguse konsonantühendeid, mis keeles sõnaalgulistena ei esine.

Soov moorad eesti keele kirjeldusest välja jätta (Lippus 2016) näib pärinevat 1960. aastatest, mil sõnu peeti lineaarseteks segmendijadadeks ning moorat mõõtühikuks, mitte omaette üksuseks prosoodilises struktuuris. Tollases, lineaarseid jadasid uurivas fonoloogias, mis lubas vaid binaarset pikkusvastandust, oli suurepärane Ilse Lehiste idee iseloomustada välteid silbiriimide kestussuhete kaudu. Tänapäevast moorateooriat kasutades saab aga näidata, kuidas need kestussuhted tulenevad sõnade erinevast prosoodilisest struktuurist: III välde on ühesilbiline jalg, II välde on raske esisilbiga kahesilbiline jalg ning I välde on kerge esisilbiga kahesilbiline jalg. III vältes sõna esisilbi muudab II vältes sõna esisilbist pikemaks jala lõpupikendus. Samuti aitab välteid eristada jalale iseloomulik toonikontuur, mis III välte sõnades peab mahtuma tervikuna esisilpi, aga II ja I välte sõnades saab muutuda kahe silbi jooksul. Ainult kestussuhteid arvutav vältekäsitlus ei suuda ühtselt aluselt lähtudes seletada vältemäärangut väga pika esisilbiga II-vältelistes sõnades (suurte, noorte) ega sõnades, kus teises silbis on diftong (hambaid, mõtteid), samuti pole sel moel võimalik selgitada seoseid erinevate nähtuste vahel (nt rõhusüsteem ja välted). Kõne mõistmisel ei ole kuulaja ülesanne arvutada silpide kestussuhteid - mis oleks eriti keeruline geminaatide puhul, kus hõlpsalt tajutavat silbipiiri polegi -, vaid sobitada kuuldu mõnesse teadaolevalt võimalikku struktuuri. Seejuures on abiks nii häälikukestused kui ka toonikontuur.

Uurimistööd on toetanud ETAG-i institutsionaalne uurimistoetus "Soome-ugri keelte prosoodiline struktuur ja keelekontaktid" (IUT2-37) ja HTM-i riiklik programm „Eesti keele ajaloo tervikkäsitlus II” (EKKM17-459). 


\section{Kirjandus}

Allen, William Sidney 1987. Vox Graeca: The Pronunciation of Classical Greek. 3. tr. Cambridge: Cambridge University Press.

As u, Eva Liina 2016. Eesti keele intonatsioon. - Eva Liina Asu, Pärtel Lippus, Karl Pajusalu, Pire Teras, Eesti keele hääldus. (Eesti keele varamu II.) Tartu: Tartu Ülikooli Kirjastus, lk 161-188.

A s u, Eva Liina, Ter a s, Pire 2009. Illustrations of the IPA: Estonian. - Journal of the International Phonetic Association, kd 39, nr 3, lk 367-372.

Bl o o m field, Leonard 1935. Language. London: Georg Allen and Unwin.

Broselow, Ellen, Che n, Su-I, Huffm a n, Marie 1997. Syllable weight: convergence of phonology and phonetics. - Phonology, kd 14, nr 1, lk 47-82.

Bye, Patrik 1997. A generative perspective on 'overlength' in Estonian and Saami. - Estonian Prosody: Papers from a Symposium. Toim Ilse Lehiste, Jaan Ross. Tallinn: Institute of Estonian Language, lk 36-70.

Chom sky, Noam, Halle, Morris 1968. The Sound Pattern of English. New York: Harper \& Row.

Crossw hite, Katherine 2004. Vowel reduction. - Phonetically Based Phonology. Toim B. Hayes, R. Kirchner, D. Steriade. Cambridge: Cambridge University Press, lk 191-231.

Eek, Arvo, Help, Toomas 1986. Rütminihked eesti keele kujunemisloos. Tallinn: Eesti NSV Teaduste Akadeemia.

E ek, Arvo, Meis ter, Einar 2004. Foneetilisi katseid ja arutlusi kvantiteedi alalt. Takt, silp ja välde. - Keel ja Kirjandus, nr 4, lk 251-271; nr 5, lk 336-357.

Eh a la, Martin 1999. Eesti väldete probleemi üks lahendusi. - Keel ja Kirjandus, nr 6, lk 378-386; nr 7, lk 453-466.

E h a la, Martin 2003. Estonian quantity: Implications for moraic theory. - Generative Approaches to Finnic and Saami Linguistics. Toim D. C. Nelson, S. Manninen. Stanford: CSLI Publications, lk 51-80.

Fox, Anthony 2000. Prosodic Features and Prosodic Structure: The Phonology of Suprasegmentals. Oxford: Oxford University Press.

F u d g e, Eric C. 1969. Syllables. - Journal of Linguistics, kd 5, nr 2, lk 253-286.

Hall a p, Valmen 1963. Fonoloogiline etüüd eesti keele väldete alalt. - Nonaginta. (Eesti NSV Teaduste Akadeemia Emakeele Seltsi Toimetised 6.) Tallinn, lk 95-122.

Hayes, Bruce 1981. A Metrical Theory of Stress Rules. PhD dissertation [käsikiri]. Massachusetts Institute of Technology.

Haye s, Bruce 1989. Compensatory lengthening on moraic phonology. - Linguistic Inquiry, kd 20, nr 2, lk 253-306.

Haye s, Bruce 1995. Metrical Stress Theory: Principles and Case Studies. ChicagoLondon: The University of Chicago Press.

Her m a n n, Gottfried 1799. Handbuch der Metrik. Leipzig: bey Gerhard Fleischer dem Jüngern.

Hint, Mati 1997. Eesti keele astmevahelduse ja prosoodiasüsteemi tüpoloogilised probleemid. Tallinn-Helsinki: Eesti Keele Sihtasutus.

Hock, Hans-Henrich 1986. Compensatory lengthening: In defense of the concept „mora”. - Folia Linguistica, kd 20, nr 3-4, lk 431-460.

Hym a n, Larry M. 1985. A Theory of Phonological Weight. Dordrecht: Foris. 
Hy m a n, Larry M. 2008. Universals in phonology. - The Linguistic Review, kd 25, nr 1-2, lk 83-137.

It ō, Junko, Mest er, Armin 2003. Japanese Morphophonemics: Markedness and Word Structure. Cambridge, MA: MIT Press.

Kager, René, Martínez-Pariciolt, Violeta 2018. The internally layered foot in Dutch. - Linguistics, kd 56, nr 1, lk 69-114.

Kavitskay a, Darya 2002. Triggers and alternations in compensatory lengthening. - Proceedings of the $21^{\text {st }}$ West Coast Conference on Formal Linguistics. Toim L. Mikkelsen, C. Potts. Somerville, MA: Cascadilla Press, lk 101-114.

Kiparsky, Paul 2003. Syllables and moras in Arabic. - Syllable in Optimality Theory. Toim C. Fery, R. van de Vijver. Cambridge: Cambridge University Press, lk 147-182.

Kiparsky, Paul 2017. Livonian stød. - Segmental Structure and Tone. Toim W. Kehrein, B. Köhnlein, P. Boersma, M. Oostendorp. Berlin-Boston: Walter de Gruyter, lk 195-210.

Köhnlein, Björn 2016. Contrastive foot structure in Franconian tone-accent dialects. - Phonology, kd 33, nr 1, lk 87-123.

L a cy, Paul de 2007. Themes in phonology. - The Cambridge Handbook of Phonology. Toim P. de Lacy. Cambridge: Cambridge University Press, lk 5-30.

Lehiste, Ilse 1960. Segmental and syllabic quantity in Estonian. - American Studies in Uralic Linguistics I. Bloomington: Indiana University, lk 21-82.

Lehiste, Ilse 1997. Search for phonetic correlates in Estonian prosody. - Estonian Prosody: Papers from a Symposium. Toim Ilse Lehiste, Jaan Ross. Tallinn: Institute of Estonian Language, lk 11-35.

Lippu s, Pärtel 2016. Eesti keele sõnaprosoodia. - Eva Liina Asu, Pärtel Lippus, Karl Pajusalu, Pire Teras, Eesti keele hääldus. (Eesti keele varamu II.) Tartu: Tartu Ülikooli Kirjastus, lk 119-160.

M c C a r thy, John 1979. On stress and syllabification. - Linguistic Inquiry, kd 10, nr 3, lk 443-466.

Mc Carthy, John J. 1986. OCP effects: Gemination and antigemination. - Linguistic Inquiry, kd 17, nr 2, lk 207-263.

Morén-Duolljá, Bruce 2013. The prosody of Swedish underived nouns: No lexical tones required. - Nordlyd, kd 40, nr 1, lk 196-248.

Nes p or, Marina, Vogel, Irene 1986. Prosodic Phonology. Dordrecht: Foris.

Pi it s, Liisi, Ka lvik, Mari-Liis 2017. Varieeruva vältega sõnade hääldusuuringud kõnesünteesi teenistuses. - Eesti Rakenduslingvistika Ühingu aastaraamat, kd 13, lk 123-140.

Pike, Kenneth L., Pike, Eunice V. 1947. Immediate constituents of Mazateco syllables. - International Journal of American Linguistics, kd 13, nr 2, lk 78-91.

Prince, Alan 1980. A metrical theory of Estonian quantity. - Linguistic Inquiry, kd 11, nr 3, lk 511-562.

Prillop, Külli 2013. Feet, syllables, moras and the Estonian quantity system. Linguistica Uralica, kd 49, nr 1, lk 1-29.

Prillop, Külli 2015. Hääliku-, silbi- ning jalavälde: ühe nähtuse mitu tahku. Eesti ja Soome-Ugri Keeleteaduse Ajakiri, nr 6 (3), lk 169-195.

R a un, Alo, S a are ste, Andrus 1965. Introduction to Estonian Linguistics. (UralAltaische Bibliothek XII.) Wiesbaden: Harrassowitz. 
Su o mi, Kari, Toiva nen, Juhani, Ylitalo, Riikka 2008. Finnish Sound Structure. Phonetics, Phonology, Phonotactics and Prosody. Oulu: Oulu University Press.

Zec, Draga 2007. The syllable. - The Cambridge Handbook of Phonology. Toim P. de Lacy. Cambridge: Cambridge University Press, lk 161-194.

Ter as, Pire 2016. Eesti konsonandid. - Eva Liina Asu, Pärtel Lippus, Karl Pajusalu, Pire Teras, Eesti keele hääldus. (Eesti keele varamu II.) Tartu: Tartu Ülikooli Kirjastus, lk 63-117.

Trubetzkoy, Nikolai 1939. Grundzüge der Phonologie. Prague: Vandenhoeck and Ruprecht.

Türk, Helen, Li p pus, Pärtel, Ši m k o, Juraj 2017. Context-dependent articulation of consonant gemination in Estonian. - Laboratory Phonology, kd 8, nr 1, lk 1-26.

Vaux, Bert, Wolfe, Andrew 2009. The appendix. - Contemporary Views on Architecture and Representations in Phonology. Toim E. Raimy, C. E. Cairns. Cambridge, MA-London: MIT Press, lk 101-143.

W e ske, M. 1879. Eesti keele healte õpetus ja kirjutuse viis. (Eesti kirjawara 1.) Tartu: Schnakenburg'i trükk ja kulu.

Y i p, Moira 2007. Tone. - The Cambridge Handbook of Phonology. Toim P. de Lacy. Cambridge: Cambridge University Press, lk 229-251.

Külli Prillop (snd 1974), PhD, Tartu Ülikooli eesti ja üldkeeleteaduse instituut, eesti fonoloogia teadur, kulli.prillop@ut.ee

\section{What is the role of mora in Estonian?}

Keywords: phonology, Estonian quantity, moraic consonant, lenis, fortis, foot

The article introduces the main principles of moraic theory and the role of mora in Estonian phonology, also addressing the history of the concept 'mora' in theoretical linguistics. In traditional studies of metrics, the term 'mora' used to refer to a minimal unit of metrical time (equivalent to a short syllable). Yet according to moraic theory, mora is a unit of phonological structure, a part of the syllable, not just a measure of length. This approach allows to explain the ternary system of Estonian quantity as well as the distinction between syllable-final lenis and fortis obstruents in a straigthforward way, which is, moreover, in good accordance with phonetical facts. Fortis obstruents in Estonian are traditionally described as sequences of two identical consonants. This is problematic because phonetic analysis has detected no consistent rearticulation during fortis obstruents. Such a sequence of identical segments also violates the universal obligatory contour principle. In moraic theory, fortis can be defined as a moraic obstruent and lenis as a non-moraic obstruent. In moraic theory Estonian quantity degrees are described as follows: the stressed syllable of Q3 fills the whole foot, whereas in the case of Q1 and Q2 the foot consists of two syllables.

Külli Prillop (b. 1974), PhD, University of Tartu, Institute of Estonian and General Linguistics, Research Fellow in Estonian Phonology, kulli.prillop@ut.ee 